\title{
Guiño, ambigüedad e incertidumbre: claves de lectura y efectos estéticos del pacto ambiguo*
}

Fecha de recepción: 01 de abril de 2017

Fecha de aprobación: 27 de junio de 2017

\section{Resumen}

A propósito de los debates actuales en torno a las definiciones de autoficción y pacto ambiguo, este artículo se ocupa de explorar sus linderos y exclusiones, y de proponer precisiones conceptuales orientadas a que encuentren cabida algunos problemas de interés creciente, pero que parecen exceder las definiciones canónicas. El énfasis se hará en los guiños textuales y extratextuales a través de los cuales se llama la atención sobre las figuraciones de autor, en el rol del lector y en los efectos de ambigüedad, debilitamiento de la verdad e incertidumbre, que se producen en las obras que suscriben el pacto ambiguo.

Palabras clave: pacto ambiguo, autoficción, figuración de autor, incertidumbre, estética débil.

Citar: Escobar Vera, H. (enero-junio de 2017). Guiño, ambigüedad e incertidumbre: claves de lectura y efectos estéticos del pacto ambiguo. La Palabra, (30), 69 - 91. doi: https://doi.org/10.19053/01218530.n30.2017.6210

\section{Hernando Escobar Vera}

Magíster en Literatura Hispanoamericana del Instituto Caro y Cuervo, Máster en Psicoanálisis y Teorías de la Cultura de la Universidad Complutense de Madrid. En la actualidad, adelanta su investigación doctoral en torno a estéticas contemporáneas en la Universidad Complutense de Madrid. Docente de la Maestría en Literatura de la Universidad Pedagógica y Tecnológica de Colombia. nandoev@yahoo.es

*Artículo de reflexión que hace parte de la investigación sobre estéticas contemporáneas que adelanto en el marco del Doctorado en Literatura Hispanoamericana de la Universidad Complutense de Madrid. 


\section{la palabra}

\section{Innuendo, Ambiguity and Uncertainty: Reading Keys and Aesthetic Effects of the Ambiguous Pact}

\section{Abstract}

Based on current debates on the definitions of autofiction and ambiguous pact, this article explores their boundaries and exclusions, proposing conceptual precisions aimed at focusing on some problems of increasing importance, that appear to exceed canonic definitions. Emphasis will be placed on textual and extratextual innuendos present in works based on the ambiguous pact, such as figurations of the author, the role of the reader and the effects of ambiguity, the weakening of truth and uncertainty.

Keywords: Ambiguous pact; Autofiction; Figuration of the author, Uncertainty; Weak form.

\section{Clin d'oeil, ambiguilté et incertitude: clés de lecture et effets esthétiques du pacte ambigu}

\section{Resumé}

Etant donné les débats actuels autour des définitions d'autofiction et pacte ambigu, cet article s'occupe d'en explorer ses limites et ses exclusions. On voudrait, ainsi, proposer des précisions conceptuelles afin que certaines problématiques porteuses d'un intérêt de plus en plus grand, trouvent une place alors qu'elles semblent excéder les définitions canoniques. Nous analyserons les clin d'oeils textuels et extratextuels à travers desquels on peut constituer des figures d'auteur, le rôle du lecteur, les effets d'ambiguïté, l'affaiblissement de la vérité et l'incertitude qui se produisent dans les oeuvres où a lieu le pacte ambigu.

Mots-clés: pacte ambigu; autofiction; figuration d'auteur; incertitude; esthétique affaiblie. 


\section{Introducción}

En medio de la gran cantidad de textos de teoría y crítica que, respecto a la autoficción, se han venido produciendo en el ámbito hispanoparlante en las últimas décadas, sobresale la atención que se les ha dispensado a dos asuntos: la tensión entre lo biográfico y lo ficcional que caracteriza esta forma narrativa, $y$ el problema de su definición.

Respecto a lo primero, Casas (2014) recuerda que el concepto surgió en los años $70^{1}$, inicialmente muy apegado al de autobiografía, «en tanto que expresión posmoderna de esta» (pp. 7-8) $)^{2}$, y a partir de los 80 se empezó a subrayar su vínculo ambiguo con la ficción.

Sin embargo, una tendencia que viene consolidándose consiste no solo en el reconocimiento del carácter ambiguo, ambiva- lente o de simultaneidad de los dos pactos, característico de la autoficción, sino en la valoración positiva de este carácter y de sus alcances e implicaciones ético-estéticos (por ejemplo, Lejeune, 1994 [1986]; Darrieussecq, 1996; Alberca, 1996, 2004b, 2005a, 2005b y 2007; Puertas, 2003; Villena, 2005; Gasparini, 2004 y 2008; Amícola, 2009; Del Pozo, 2009; Diaconu ${ }^{3}, 2010$ y 2013; Musitano, 2010; Escobar, 2015; Hernández, 2016). Al igual que en la oposición entre historia y literatura, a propósito de la literatura histórica, desde esta perspectiva se ha insistido en el cuestionamiento de la verdad biográfica (e histórica ${ }^{4}$ y se han reivindicado tanto el valor de 'verdad' de lo imaginario y lo ficcional, como la pertinencia estética de los efectos de ambigüedad. Es en el marco de esta tendencia donde se sitúan las reflexiones que se desarrollarán en las siguientes páginas.
El segundo objeto de debate ha sido qué cabe estudiar bajo dicha denominación frente al interés de algunos investigadores por incluir asuntos que exceden la definición canónica 5 . El problema, desde luego, no es la relevancia de dichos asuntos, sino su ajuste a las categorías teóricas. Al respecto, es adecuado establecer dos distinciones: la primera, entre pacto ambiguo y autoficción; y la segunda, entre la autoficción como forma y como clave de lectura.

A continuación, se abordarán las dos distinciones como marco para situar los problemas derivados de las nuevas figuraciones de autor (textuales $\mathrm{y}$ extratextuales) que tienen como correlato nuevas agencias para el lector, en un tipo de relación autor - guiño autoficcional lector cuyos efectos apuntan a la ambigüedad, al debilitamiento de la verdad y a la incerti-

1 Aunque las nociones teóricas de autoficción y pacto ambiguo son relativamente recientes, esto no quiere decir que las formas a las que aluden no existieran previamente. Quizás el ejemplo más sobresaliente sea la alusión que Cervantes hace a sí mismo, en clave autoficcional, en el segundo volumen de Don Quijote (1615). Es evidente que las categorías teóricas no apuntan a crear nuevas realidades (al menos, no siempre), sino a describir realidades preexistentes, con el fin de facilitar su estudio. Esto, sin desmedro del hecho de que los cultivos tanto de la autoficción como de la metaficción vienen ocupando un lugar sobresaliente en las literaturas catalogadas como posmodernas. Dicha tendencia, en sí misma, merece la atención de la crítica.

2 En el mismo sentido, Alberca (2005a) destaca los trabajos de Doubrovsky (1988), Lecarme (1993) y Vilain (2005), para el primer caso, y de Darrieussecq (1996) y Colonna (2004), para el segundo.

3 Diaconu (2013) expone su preferencia por el concepto de ambivalencia.

$4 \quad$ No son pocas las correspondencias entre novela histórica y autoficción que se observan en los debates de la crítica. El cruce entre las dos es referido brevemente por Alberca (2007) en estos términos: «El fenómeno actual no se caracteriza ya por la inclusión de elementos autobiográficos o fragmentos históricos [...] no se trata solo del uso ocasional de éstos para dar mayor verosimilitud a la novela, sino de la construcción entera de la novela como un simulacro autobiográfico o histórico» (p. 287). Juliá (2006) identifica el cruce a propósito de El coro a dos voces. Una novela de relatos (1997) de Fernando Quiñones. Finalmente, Martínez (2014) hace una aproximación en un sentido similar, pero a propósito de la fotografía: en su texto establece vínculos entre docuficción y autoficción.

5 Me refiero a la que propone Lecarme (1993), acogida por Alberca y retomada en buena parte de los textos de teoría y crítica. 
dumbre como efectos estéticos $\mathrm{y}$ de sentido ${ }^{6}$.

\section{Primera distinción: pacto am- biguo y autoficción}

La noción de pacto de lectura deriva de la taxonomía pragmática de los actos de habla (Searle, 2001 [1969]), si bien, para pensar específicamente el pacto literario, se asimilan la caracterización desarrollada por Ingarden (2005 [1937]) del proceso de aprehensión que hace (o debería hacer) el (buen) lector de literatura y los desarrollos posteriores que hacen el estructuralismo y las estéticas de la recepción, especialmente en torno a pacto y contrato ${ }^{7}$. El pacto orienta la actitud del lector (Lejeune, 1986 1975, p. 65), articula «el compromiso y el sistema de presentación elegido por el autor, y el modo de lectura elegido por el lector» (Lejeune, 1986, p. 133) y se refiere a las expectativas que este se crea frente a un texto y a cómo las va actualizando a medida que se encuentra con las claves de lectura que el mismo texto le provee.

En procura de establecer las particularidades del pacto autobiográfico, Lejeune (1994 [1975]) define la autobiografía por la identidad nominal entre autor y personaje, y no por sus semejanzas, como ocurriría en la novela autobiográfica. Esto lo denomina «contrato de identidad» (p. 72). Así mismo, diferencia los dos pactos a través del criterio identidad-no identi$\mathrm{dad}^{8}$. No obstante, nota la posibilidad de que el protagonista de una novela tenga el mismo nombre de su autor, un caso que rompería la clara oposición de los dos pactos o crearía, así fuera artificialmente, una zona de intersección entre los dos; sin embargo, en su texto de 1975 no ofrece ningún ejemplo, no desarrolla los alcances de esa posibilidad ni le asigna un nombre al fenómeno?.

Es Alberca (1996), el teórico más influyente respecto al tema en el ámbito hispanoparlante, quien propone la denominación de pacto ambiguo (p. 12), y remarca que «hay una gran variedad de formas y estrategias a caballo de estos dos grandes pactos [el autobiográfico y el novelesco] y por tanto una infinidad de posibilidades y grados de ambigüedad» (Alberca, 2005a, p. 117).

Es decir, el pacto ambiguo es un campo de posibilidades formales que produce horizontes de expectativas lectoras diferenciables de los que se implican, de un lado, en los géneros de no ficción y, de otro, en los géneros ficcionales. Un pacto responde a un género, pero no es un género. Por tanto, aunque el pacto ambiguo es el pacto que conlleva la lectura de la forma autoficcional, no se corresponde exclusivamente con esta forma. Como campo de posibilidades, la alberga, junto con otras bastante menos exploradas.

A pesar de referirse a una «gran variedad de formas y estrategias», Alberca (2015a) se concentra en la forma autoficcional y solamente la diferencia de una

6 El énfasis se hará en la narrativa, pero no porque se quiera desconocer que el fenómeno, o serie de fenómenos íntimamente ligados (llámense autoficción, autofiguración, performancia de sí o automercadeo), rebasa los límites, no solo de la literatura, sino también de las artes, como una tendencia que, sin duda, dice algo sobre las búsquedas expresivas y las sensibilidades contemporáneas.

7 Lejeune (1994 [1986], p. 132) y Pérez (2012) se ocupan de los matices que diferenciarían los dos términos (pp. 27-28).

8 En todo caso, reconoce que el lector puede intentar constatar si el contrato se viola, a través de la puesta en relación entre el texto y la vida real. Más tarde, añade que la autobiografía pertenece a dos sistemas: uno referencial y otro literario (1994 [1986], p. 133) y aclara que el pacto autobiográfico diferencia una autobiografía de una novela con contenido autobiográfico en tanto, en la última, el lector no espera que lo que se le cuenta sea cierto, aunque pueda haber coincidencias entre las vivencias factuales del autor y las atribuidas a un personaje con un nombre diferente (1994 [1975]). En 2004, lo puntualiza en estos términos: el pacto autobiográfico «es la promesa de decir la verdad sobre sí mismo. Esto se opone al pacto de ficción» (entrevista con Alberca, 2004a). Resumiendo, de acuerdo con Lejeune, el pacto autobiográfico residiría en la identidad nominal autor-protagonista de la narración y en la promesa, explícita o tácita, de contar la propia vida

$9 \quad$ En «El pacto autobiográfico (bis)» (1994 [1986]) acoge los desarrollos posteriores que le dan lugar a la autoficción en su casilla vacía de 1975 . 
forma no autoficcional: la novela autobiográfica ${ }^{10}$. Y así como en el caso de Alberca, este campo de posibilidades ha tendido a cerrarse excesivamente en torno a la autoficción. Esto ha ocurrido, o bien porque en efecto los investigadores están interesados en fenómenos que quedan bien acotados bajo esta categoría ${ }^{11}$, o bien porque, necesitando abordar fenómenos que la exceden, insisten en emplearla de un modo que fuerza los márgenes de su definición canónica y, en ocasiones, confunde la forma (autoficción) con el pacto (ambiguo).

De manera que los estudios desde la perspectiva del pacto ambiguo bien pueden ampliar su objeto fuera de los límites de la autoficción, dando cabida a otras formas que impliquen la presencia ambigua del autor $o$ de sus proyecciones en el texto, pero, también, a fenómenos del orden de la figuración extratextual $^{12}$, que susciten o estimulen la percepción de ambigüedad por parte del lector. Seguramente sea necesario establecer, con cuidado, los linderos del pacto ambiguo, pero los de la forma autoficcional se presentan demasiado estrechos.

\section{Segunda distinción: la auto- ficción como forma o como clave de lectura}

La definición de autoficción que se ha hecho canónica fue propuesta por Lecarme (1993), para quien consiste en «una narración cuyo autor, narrador y protagonista comparten la misma identidad nominal y cuyo título genérico indica que se trata de una novela» (p. 227). ${ }^{13}$ Analicemos las cotas de esta definición y lo que excluyen: (UNO) el tipo de identidad que debe presentarse entre autor, narrador y personaje, (DOS) el modo en que debe expresarse, (TRES) la fórmula trinitaria misma; y (CUATRO) la vinculación genérica:

(UNO) El criterio relevante en la definición canónica de la autoficción como forma no es la correspondencia entre la experiencia o recorrido biográfico del autor y los hechos representados en la narración, sino la identidad nominal autor-narrador-personaje. Al respecto, Alberca (2015a) enfatiza en que

[...] otras interpretaciones que tienden a considerar como autoficción cualquier relato novelesco en el que sean reconocibles materiales o contenidos autobiográficos, pero sin ninguna señal que acredite la identidad de autor $y$ de personaje, me parecen demasiado generales y vagas, y de tenerlas en cuenta habría que considerar buena parte de las novelas conocidas como autoficciones (p. 118).

En efecto, lo que caracteriza la autoficción no es el simple volcamiento en la ficción de la experiencia biográfica, lo cual es característico de prácticamente toda literatura. Por ejemplo, cuando Flaubert afirma provocadoramente: «Madame Bovary, c'est moi», a lo que se refiere es a que ha vertido aspectos de su sensibilidad y su experiencia en la construcción del personaje, como seguramente

10 Alberca (2005a) explica que se debe distinguir entre autobiografía ficticia o fantástica -una forma de autoficción- y novela autobiográfica -una forma que, aquí consideramos, cabe en el pacto ambiguo, si bien, en acuerdo con Alberca, no en la autoficción entendida como forma. En la primera hay coincidencia nominal entre autor y personaje, pero no entre la experiencia biográfica de estos, es decir, se trata de una autobiografía simulada o pretendida. En la novela autobiográfica, dice, ocurre lo contrario: no hay identidad nominal, pero sí coincidencia de las trayectorias biográficas, es decir, hay un autobiograficismo escondido: «el autor se encarna total o parcialmente en un personaje novelesco, se oculta tras un disfraz ficticio o aprovecha para la trama novelesca su experiencia vital debidamente distanciada mediante una identidad nominal distinta a la suya» ( $p$. 116).

11 En todo caso, la autoficción, en sí misma, abarca una importante diversidad de opciones, como lo muestra Alberca (2005a y 2007).

12 Son plausibles los aportes de algunos teóricos que proponen categorías que colindan o tienen zonas de intersección con la autoficción, pero que son diferenciables de ella y permiten concentrarse en la particularidad de nuevos objetos de estudio que implican la figuración textual del autor o su ficcionalización textual o no. Es el caso de Premat (2009).

13 Trad. ad hoc. 
lo hace la mayoría de escritores. En cambio, en el caso de la autoficción, este volcamiento puede ser o no ser, puesto que el autor puede atribuir al personaje con el que comparte identidad nominal vivencias radicalmente opuestas a las suyas o provistas de la más volátil fantasía.

(DOS) La identidad no debe ser entonces experiencial sino nominal, y la explicitud del nombre propio sería su marca más evidente; no obstante, Alberca (2005a) admite que dicha identidad se puede establecer también «de manera implícita [...] puede ser sugerida o sustituida por algún otro rasgo o faceta del escritor, que permita identificar inequívocamente al autor» ( $\mathrm{p}$. 119). En este caso, es el adverbio 'inequívocamente' el que puede cerrar la puerta a ciertas aproximaciones y ser fuente de polémica $^{14}$.

(TRES) La no necesariamente santísima trinidad autor-narrador-personaje es otra limitación que invita a la rebeldía frente a la definición canónica, puesto que no siempre la intención autoral de llamar ambiguamente la atención sobre su figura va a quedar representada en un narrador-protagonista que lleve su nombre u otros rasgos nominales: puede quedarlo también a través de un narrador que lleve su nombre y se presente como fautor, editor o testigo de una historia ajena, aunque matizada por su punto de vista, es decir, que narre una historia de la que no es protagonista; a través de un personaje con su nombre pero cuya historia no es narrada por él mismo, o, en fin, a través de un personaje secundario (incluso al modo de los paneos a través de los cuales algunos directores se proponen un punto de encuentro lúdico con sus espectadores, o de la representación de escenas en las que los pintores se retratan como parte de alguna comitiva).

(CUATRO) En su definición, Lecarme alude al título genérico de novela combinado con las anteriores características; sin embargo y aunque la mayoría de estudios se concentran en autoficciones concebidas como novelas o abordadas en oposición a este género, Alberca (1996, 2004b, 2005a) propone no excluir el cuento y concentrar el énfasis en la identidad nominal que, para él, es el único requisito imprescindible de la autoficción, «signo clave de la propuesta autoficcional sin el cual ésta quedaría sin sentido» (Alberca, 2005a, p. 118). En efecto, la vinculación genérica a la novela es un rasgo poco pertinente para la definición: no sobresale ninguna razón que justifique la restricción de la autoficción como forma a aquellos textos que se presenten bajo la etiqueta de novela o que sean equiparables a ella, puesto que la identidad nominal, sobre la que tanto se ha insistido, también es posible en el cuento y otras formas narrativas.

La autoficción se define así, en principio, como una forma narrativa, lo cual excluiría otros géneros literarios -la poesía y la dramaturgia-, y otras artes. He aquí una segunda limitación polémica $^{15}$.

En la identidad nominal, pues, radica la definición estructural de una forma que entraña un grado notable de particularidad en el concierto de las formas narrativas (cuento y novela). Este rasgo, sin embargo, es insuficiente para afirmar que la autoficción constituye un género diferenciable de los otros dos. Al contrario, esta forma se inserta en los dos géneros, al lado de otras formas, como la policíaca, la erótica, la histórica, la

14 Por ejemplo, Alarcón (2014) señala la posibilidad de textos autoficcionales sin que se explicite nominalmente la proyección del autor como personaje, a través de la idea propuesta por Vincent Colonna del texto como proyección especular del autor, la cual, sostiene, desvela los mecanismos que generan la ambigüedad característica de la autoficción.

15 Es importante el aporte de los investigadores que han intentado pensar las cuestiones de la autofiguración y sus efectos, a propósito de otras disciplinas artísticas, aunque en algunos de estos trabajos también se incurre en la confusión entre pacto y forma. En fotografía: Ramírez (2003), Pérez (2008), Tabachnik (2012), Pardo (2012), Goyarrola (2016); en cine, video-arte y teatro: Bellour (1990), Trastoy (2006), Martín (2008), García (2009, 2014), Toro (2010), Álvarez (ed.) (2013), Gómez-Tarín y Rubio-Alcover (2013), Alarcón (2014), Cabo (2014). 
de aventuras, la de terror, la de ciencia ficción, etc. ${ }^{16}$

Pero aún queda sin resolución el problema de los límites polémicos y las exclusiones que implican la definición e, incluso, las flexibilizaciones que aquí se han acogido o propuesto:

Quizás sea razonable aceptar la colonización del término a través de su definición canónica como forma narrativa; aun así, no se puede desconocer que el término 'autoficción' remite a la reflexividad de la acción de ficcionalizar; es decir, remite a la acción de hacer o proyectar una ficción de sí mismo (no solo a la acción de escribirla, y no solo como cuento o novela, porque ¿se puede anegar tan tajantemente la cuestión de la ficción para la poesía y el teatro?). De manera que si, por un lado, la definición canónica trazó cotas al pensar la autoficción como una forma particular en el marco de la narrativa de ficción, la expresión, en sí misma, invita a desbordar estas cotas y a pensar otros fenómenos que atañen a las representaciones ambiguas del autor tanto en el campo lite- rario como en otros campos artísticos e, incluso, por fuera de las obras ${ }^{17}$, a modo, por ejemplo, de performancia de sí o de automercadeo.

En cualquier caso, estos tres cercados (identidad nominal inequívoca, trinitarismo y circunscripción al género narrativo), quizás muy débiles, o desgastados, o innecesariamente fuertes, que marcan linderos de la definición de autoficción como forma, se han convertido en invitaciones a trasponerlos y a traer al campo de la autoficción asuntos que no cabrían si nos atuviéramos estrictamente a su definición canónica. Las alternativas son o no ser tan estrictos o dar un lugar adecuado a dichos asuntos, de cuya relevancia no se duda.

A modo de alternativa, aquí se propone comprender la autoficción no solo como una forma contenida en el marco de la definición estructural ya expuesta -una forma relevante, interesante y diversa, en cualquier caso-, sino también como una clave de lectura que se inscribe en el marco del pacto ambiguo y responde al carácter igualmente ambiguo de las figuraciones de autor que se proyectan en ciertas obras de un modo textual o de otros modos.

Una clave de lectura autoficcional le es recíproca a un gesto intencionado $\mathrm{y}$, por tanto, significativo del autor, un guiño -textual o extratextual (declaraciones, apariciones públicas, figuraciones mediáticas, etcétera)- que motiva o actualiza determinadas expectativas respecto a la proyección de su figura en su obra. Si se trata de un gesto textual, se puede buscar su correspondencia (y provocación) en una clave de composición (la referencia nominal u otra clave), la cual plasma la intención autoral y apunta a lograr algún efecto en el lector. Así, el efecto y la clave de lectura laten desde el texto.

Con estas distinciones también se ha querido destacar que, en estos campos de estudio, el interés se ha venido desplazando de la forma al pacto y a los efectos estéticos y de sentido que este conlleva, en la medida en que la potencia estética no reside

16 A primera vista, parece que los teóricos de la autoficción la han diferenciado en términos genéricos de la novela y la autobiografía, por lo cual se implicaría que se trata de un género diferente de aquellos; sin embargo, no se debe perder de vista que la distinción fuerte en realidad se ha hecho en torno a los pactos, no a las formas y que, como se dijo, el propio Lecarme (1993) considera la autoficción en el marco de la novela. Adicionalmente, si se sitúa la autoficción al lado de otras formas del cuento y la novela, como las arriba enlistadas, se puede verificar que el hecho mismo de que se expresen dentro de los estándares de los dos géneros atestigua que sus particularidades no son del orden de lo genérico. Que ninguna de estas formas constituya un género independiente explica, además, sus posibles cruces: por ejemplo, es posible que se presente un cuento que sea histórico, erótico y de autoficción.

17 Se han propuesto otros conceptos, bien para salvar los escollos de la colonización del término 'autoficción', bien para señalar la especificidad de objetos de estudio afines y vecinos, pero diferentes; por ejemplo: autodrama (García, 2014), turismo identitario (Tabachnik, 2012), auto(r)ficción (Toro, 2010), autofiguración (Premat, 2009), ficciones de autor y mitografía autoral (recogidos por Premat, 2009). 
en la autoficción como forma configurada en términos estructurales, sino en la ambigüedad del pacto del que la forma autoficcional participa, al lado de otras formas y de otros problemas afines que enriquecen la discusión.

\section{El guiño: clave de lectura au- toficcional}

Como ya se ha señalado, no es ninguna novedad que el escritor vuelque aspectos de su personalidad, su forma de ver el mundo o sus vivencias en los personajes que construye; lo especialmente interesante del pacto ambiguo no es ese volcamiento, que puede tener lugar en diversos grados o en ninguno en absoluto; lo interesante es una especie de sombra o espectro que atraviesa las páginas de las obras que lo suscriben y que produce una clave de lectura, un gesto, que hace pensar en la figura del autor. Este espectro va varias calles adelante del lector $y$, cada vez que dobla la esquina, le guiña el ojo, invitándolo a seguirlo. Al lector su silueta se le hace familiar, la forma de su nariz, los pasos alegres o taciturnos, el abrigo de colores llamativos o el paraguas inadecuado para un día de sol.

El lector seguiría al personaje, en cualquier caso, en el marco de cualquier pacto; pero este personaje en particular le guiña el ojo. Su gesto y su manera de doblar la esquina antes de dejarlo, estar seguro de si es o no aquel que conoce o cree conocer, es el que lo anima a la persecución. La forma del caminante fantasmal de afirmar, con un guiño, «aquí estoy yo», desaparecer y generar en el lector la incógnita: «¿Aquí?, ¿dónde?» reduce la presencia del autor a huella textual, indicio. Así ocurre también en el autorretrato: de acuerdo con Bell (2007), «lo que distingue el autorretrato de la pintura de figuras en general es la presencia de alguna indicación del "aquí estoy yo"» (p. 8); sin embargo, esta indicación no es una promesa, sino un guiño y una provocación.

Imaginemos una pintura en la que el artista se represente a sí mismo bajo el título Autorretrato con guiño, imaginemos otro en el que el guiño no haga parte del título sino de la representación, y otro más en el que la imagen esté acompañada de la frase «Este no soy yo», como hace René Magritte (1898-1967) con la pipa ${ }^{18}$, para recordar que el signo icónico no es lo que representa. Las claves de lectura son la denominación 'autorretrato', el guiño -tanto en el título como en la representación-, el intertexto 'este no soy yo' y los elementos compositivos que puedan provocar en el observador la idea de semejanza entre artista y representación $^{19}$. Pero estos elementos se ironizan mutuamente, de manera que la afirmación se transforma en pregunta y en incógnita: «¿Este no es él?».

Imaginemos ahora uno sin rostro $y$, por tanto, sin guiño expresado visualmente, y denominado también Autorretrato, uno en el que solo se ve la espalda de un hombre o los aperos de un viajero, como ocurre en la serie de autorretratos (años 80) de Eduardo Úrculo (1938-2003). Imaginemos autorretratos abstractos, absurdos o también creados en clave realista, con tanta fidelidad como una fotografía, en los que el artista claramente parece estar ahi $\mathrm{y}$, sin embargo, se destaca una pose que absorbe la mirada del observador e ironiza el conjunto de la composición: la pose, el código de la representación, el estilema, todos guiños, reiteran la incógnita: «¿Este no es él?”.

Priego (1985) sitúa el autorretrato en el marco del retrato, pero con una salvedad:

en el retrato la acción es transitiva: hay un sujeto (artista), alguien que la recibe (modelo) y un com-

18 En su serie La trahison des images (1928-29); la frase es «Ceci n'est pas une pipe».

19 Ese parecer estar ahí con la potencia de lo visual en el autorretrato, así como la variedad de sus motivos y los nexos que se pueden establecer con los motivos y maneras de parecer estar ahí del autor en las escrituras del pacto ambiguo es el objeto de mi investigación actual y de un par de artículos en curso. 
plemento directo (obra), mientras que el autorretrato equivale a una oración reflexiva porque la recibe el mismo sujeto que actúa y se identifican artista $\mathrm{y}$ modelo. Por esto se añade a 'retrato' el prefijo griego 'auto' en las lenguas latinas, y el 'self' en las germánicas, indicativo de esa reflexividad básica ( $\mathrm{p}$. 177).

Bien se podría deslizar este planteamiento a las escrituras del pacto ambiguo: autor-personaje-texto; sin embargo, en esta ecuación, tanto para la pintura como para la escritura, falta un agente. Pensar una triada que incluya también al lector remite al modelo clásico de la comunicación: emisor (autor) - mensaje (texto) - receptor (lector). No obstante, aquí no quedan recogidas la reflexividad que destaca Priego ni el rol específico que se le asigna al observador-lector, puesto que ¿a quién va dirigido el guiño, ante quién se ironiza, a quién se le recuerda que la representación difiere de lo representado?
El autor en el texto no es carne sino ícono, no es pie sino huella, indicio. Aun así, el vertimiento de algo del autor dentro de la obra produce el vertimiento recíproco de algo del lector, incitado a participar del juego. Este vertimiento produce, a su vez, un desborde del texto. Lo que produce este flujo (vertirse-desbordarse), este oleaje, es un gesto nominal, el equivalente a la representación icónica del rostro, o algo más vago: un guiño.

Las acepciones y connotaciones de esta expresión, que ya se ha venido empleando en la teoría de la autoficción ${ }^{20}$, en realidad le dan a la vaguedad de su uso unos contornos bastante interesantes. Más allá de la más evidente: «mensaje implícito», la expresión también designa la acción de «cerrar un ojo momentáneamente quedando el otro abierto, a veces con disimulo por vía de señal o advertencia», la de «entornar los párpados ligeramente, por efecto de la luz o por mala visión»» y la de «resplandor vivo y efímero» (RAE, Edición del Tricentenario). El guiño connota la invitación, la seducción, el disimulo, el mensaje íntimo y cifrado, pero también la ironía, la señal de alerta y lo inasi- ble del resplandor efímero: lo que se escapa a la mirada, el reconocimiento de que algo la atrae intensamente, pero también la desborda. El guiño, pues, sintetiza las claves que constituyen la ambigüedad e incógnita del pacto.

De manera que, daremos por sentado los elementos relativos al texto comunes a toda literatura, y nos concentraremos en lo que hay allí de sombra o espectro de autor, un fantasma que se convoca a través de algún guiño textual, elemento central, aunque sutil, en la composición, al cual responde el lector con su propio guiño, señal de complicidad y aceptación del pacto. Al interior del texto, nos concentraremos en la siguiente relación: proyección del autor - guiño - rol del lector, $y$, a partir de esta concepción, en la agencia que se le da al lector y en los efectos estéticos y de sentido del pacto ${ }^{21}$.

\section{Figuraciones de autor}

Consideremos que el autor ${ }^{22}$ ha muerto, como lo dictaminó Barthes (1987 [1968]), en pleno ejercicio de potestades forenses, y como lo han reiterado

20 Por ejemplo, en Alberca, 2005a; Del Pozo, 2009, y Sánchez, 2010. Alberca (2005a) emplea el término cuando alude al tono y el significado de la dedicatoria de la primera edición de La tía Julia y el escribidor que «tendía un puente evidente, un guiño al lector, entre el texto novelesco y la realidad extratextual que lo alimenta» (p. 125). Sánchez lo emplea para hablar acerca de la "tangencialidad" en la obra de la trayectoria vital atribuible al autor (p. 2).

21 Caracterizado por su ambigüedad -hibridez (Puertas, 2003), simultaneidad (Diaconu, 2010; Musitano, 2010), yuxtaposición, solapamiento, asimilación, trastocamiento- de lo factual y lo imaginario. Esta ambigüedad se puede expresar, por ejemplo, en forma de ironía (Musitano, 2010; Muñoz, 2016), paradoja (Gasparini, 2004 y 2008; Musitano, 2010) o explicitud y reivindicación de lo imaginario (Escobar, 2015).

22 Por cuestiones de espacio, aquí no se ahonda en las concepciones del autor. Se comparte parcialmente con Lejeune (1994 [1975]) que «El autor no es una persona. Es una persona que escribe y publica. A caballo entre lo extratextual y el texto, el autor es la línea de contacto entre ambos» (p. 61) y que, en el caso de la autobiografía, como en las obras del pacto ambiguo, el uso del nombre propio fomenta la confusión entre autor y persona (p. 73); pero precisamente esta confusión permite considerar el pie que el autor tiene puesto en al factualidad. 
los sufragios, velorios y conmemoraciones que han significado las constataciones de la crítica. Pero si es así, ¿qué o quién atraviesa las páginas de los textos auto y metaficcionales que, se dice, caracterizan las literaturas posmodernas y por qué el mercado literario insiste tanto en la figura del autor y este, en su propia figuración mediática? ¿En verdad ha resucitado o tan solo se ha logrado invocar su fantasma?

La proclama de su muerte es comprensible si se la entiende como una reacción a: (UNO) los excesos de la crítica biograficista, tan extendida desde finales del siglo XIX, la cual persistió a pesar de los esfuerzos del formalismo y sigue teniendo ecos en nuestros días; (DOS) la demanda de realidad y compromiso social que se quiso imponer sobre los escritores por parte de ciertos sectores del campo cultural: morir desresponsabiliza de las deudas de todo tipo, incluidas las ideológicas, y (TRES) el cuestionamiento a que si el autor es el origen del texto, su intencionalidad debería imponerse sobre las interpretaciones de los lectores ${ }^{23}$.

Por otra parte, dicha proclama no es convincente si se la asume más acá de su carácter hiperbólico y provocador. Algunos rasgos hiperbólicos son los siguientes:

(UNO) Barthes afirma que «la escritura es la destrucción de toda voz» (p. 65) y que «en cuanto un hecho pasa a ser relatado [...] la voz pierde su origen, el autor entra en su propia muerte, comienza la escritura» (pp. 65-66). Sin embargo, la escritura no destruye, tan solo erosiona la voz, la ideología. Lo ideológico, propio de las tomas de posición conscientes del autor o filtrado desde los ecos de la cultura o desde lo inconsciente, no tiene por qué dejar de ser objeto de la interpretación, especialmente, porque constituye un núcleo del proyecto artístico autoral. No ocurre, pues, la destrucción sino la erosión de la ideología y la intencionalidad.

(DOS) Con la muerte del autor, Barthes traslada la agencia a la escritura y al lenguaje. Pero que sea «el lenguaje, y no el autor, el que habla» (p. 66) contrasta con la metáfora de la escritura como un campo de batalla en el que «lenguaje e invención son enemigos fraternales y de esa lucha nace la literatura» (Cortázar, 1994 [1979]), puesto que es el autor quien, en la escritura, se apropia del lenguaje habitado de «intenciones ajenas», «en la frontera entre lo propio y lo ajeno" (Bajtín, 1989 [1935], pp. 110-111), para oponerlo a su necesidad artística de producir signos que subviertan dichas intenciones, esto es, para producir nuevos significados. En efecto, la intención y la ideología autorales se hacen textuales, efectos latentes, lo cual es diferente de afirmar su irrelevancia.

(TRES) También es provocador el anuncio del nacimiento del lector -al que Barthes le atribuye con carácter exclusivo el lugar en que se recoge toda la multiplicidad del texto, ese «tejido de citas provenientes de los mil focos de la cultura» (pp. 69 - 71)-, con el costo no solo de la muerte del autor (p. 71) como si se pudiera ser autor sin ser el primer lector de la obra-, sino también de la del crítico (p. 70). Pero si autor y crítico habitan la misma dimensión que habita el lector, ¿se imaginó Barthes alguna especie de agujero negro que habría entrado en esta dimensión y habría devorado únicamente a dos de sus habitantes, dejando al otro intacto y fortalecido? Si habitan la misma dimensión, la muerte o alejamiento del uno, necesariamente implicaría el mismo destino para el otro. El autor no muere, sino que se hace implícito, del mismo modo que el lector. En efecto, el lector que nace es tan solo el lector de las estéticas de la recepción, porque ¿cómo dar cuenta del otro lector, el de carne y hueso, si no

23 De hecho, Barthes condonaría la pena de muerte y daría un nuevo nacimiento al autor si no se afirmara su ascendencia sobre la obra, igual que "un padre respecto a su hijo", sino que se concibiera que "el escritor moderno nace a la vez que su texto" (p. 68). 
es como objeto de estudio de la Sociología de la Literatura o el Cognitivismo? En cuanto al crítico, ¿de qué modo puede quedar este excluido de la función de lector, a menos que sea desde un enfoque prescriptivo que, de un lado pontifica sobre lo que un lector debe y no debe hacer, $y$, de otro, reclama su libertad? En otras palabras, no son irrelevantes las interpretaciones de autor y crítico, pero son tan solo eso, interpretaciones, que entrar a dialogar con las de los demás lectores.

Con lo anterior no se quiere decir que Barthes estuvo equivocado: si el modo de significación de su discurso es la hipérbole, es necesario quitar la corteza para alcanzar la almendra de su postulado. Lo que se nombra bajo la sentencia de muerte del autor es tan solo un desplazamiento de la atención, de su figura de carne, hueso y múltiples máscaras, al discurso literario. Más preciso, pero desde luego menos estimulante, sería hablar no de su muerte, sino de su empequeñecimiento, «como una estatuilla al fondo de la escena literaria" (p. 68).

Sin embargo, dos fenómenos vuelven a llamar la atención sobre la figura, factual o representada, del autor. De un lado, con las literaturas del pacto am- biguo, sin que se produzca un nuevo desplazamiento, el autor implícito adquiere una figuración en alto relieve. De otro, la figuración extraliteraria del autor incide en el pacto de lectura que se establece con el lector $\mathrm{y}$, en efecto, produce algún tipo de desplazamiento, pero no hacia la explicación biograficista de la obra, sino hacia las búsquedas de sentido respecto a los gestos performativos $\mathrm{y}$ de mercadeo del autor, con efectos tanto en las dinámicas de los campos literarios como en las expectativas del lector, es decir, en el pacto. El autor, entonces, no es irrelevante; su figura constituye, aunque sea, una provocación y, dentro de la obra, un signo (símbolo, ícono, índice, síntoma, indicio, como se mostrará más adelante).

Premat (2009) aboga por la atención que merece el autor como aspecto del texto y fuera de él y nombra diversos abordajes de estos fenómenos que él enmarca bajo el concepto de figuración de autor ${ }^{24}$. Además de la categoría autoficción, se refiere a las ficciones de autor y la mitografía autoral. Distingue entre «las ficciones de autor, en tanto que relato, y las figuras de autor, en tanto que imagen» (p. 12) y añade que la ficción de autor sería, al igual que el nombre, parte integrante de la función-autor propuesta por Foucault (p. 13). En cuanto a las mitologías autorales, dice que pueden, en casos extremos, existir independientemente de lo escrito y funcionar como relatos más o menos ficticios $\mathrm{y}$ económicamente suficientes e, inclusive, ser el resultado de un proyecto personal, bastante explícito (pp. 23-24).

De este modo, el concepto de figuración de autor incluye $\mathrm{y}$ excede el de autoficción como forma, en tanto da cabida al estudio del autor que inventa una imagen de sí mismo tanto afuera (performancia) como adentro del texto, pero no solamente a través del nombre propio, sino también de otros gestos, como la afinidad ideológica. Para ejemplificar el último asunto, Premat menciona la relación de Cortázar con Morelli (Rayuela) y con «el que te dije» (El libro de Manuel).

Dos fenómenos notables que caben en el marco de la autofiguración son el de la performancia ${ }^{25}$ y el del automercadeo. Salvador Dalí quizás sea una de las figuras que mejor encarna las dos categorías y la conciencia sobre su relación estrecha (Escobar, 2016), por ejemplo, cuando dice: «Mi estrategia me vale innumerables escritos sobre mi personalidad [...]

\footnotetext{
24 En un sentido diferente, Pozuelo (2010) emplea la expresión «figuración del yo», a través de la cual prioriza la textualización de la voz autoral y elude su puesta en contraste con la vida y posicionamientos del autor en la realidad.

25 La noción de performancia de sí encuentra un antecedente destacado en la reflexión de Foucault (2002 [1984]) sobre el dandismo de Baudelaire, cuando se refiere a "hacer de sí mismo una obra de arte" (p. 26).
} 
Gracias a mí, llegará un día en que las gentes se verán forzadas a ocuparse de mi obra» (Dalí, 2010 [1964], p. 66).

De un modo que parece recoger las dos cuestiones, la performancia y el mercadeo, Premat aborda la invención de una figura de autor como «la puesta en escena de una identidad atractiva, enigmática y ficticia» (p. 12). En un sentido similar, Meizoz (2007) hace énfasis en la incidencia que tiene en la lectura la imagen pública que los escritores construyen de sí mismos, si bien reconoce que la relación autor-lector, en todo caso, se proyecta en lo textual. Asimismo, Gasparini (2004, 2008) destaca la recepción paradójica de la autoficción, a través de informaciones contenidas tanto en el nivel textual como en el extratextual. En tal sentido, la figuración autoral extratextual adquiere el carácter de paratexto.

Así, como parte de alguna estrategia de mercadeo o de algún proyecto artístico o como expresión de determinados tipos de carácter, hoy son comunes en el campo literario colombiano escritores que llaman la atención sobre sí extratextualmente. Es el caso de Fernando Vallejo (Medellín, 1942): declaraciones y videos; Efraím Medina (Cartagena, 1967): desnudos en las portadas de libros, artículos y declaraciones pretendidamente iconoclastas; Carolina Sanín (Bogotá, 1973): columnas y publicaciones polémicas en Facebook; Jaime Espinal (Medellín, 1980): un video autoficcional en el que inventa una trayectoria como actor porno; Margarita Posada (Bogotá, 1977): un desnudo en la revista Soho acompañado de uno de sus relatos, o Marta Orrantia (Bogotá, 1970): alguna columna polémica.

Así no se pueda verificar una intencionalidad -ni mucho menos, su especificidad estética-, estos gestos autorales inciden en las expectativas de los lectores respecto a las obras, en su recepción en términos cuantitativos e, incluso, en las representaciones que los lectores pueden hacerse de los personajes, sean estos autoficcionales o no. Estos diferentes modos de recepción se observan en torno a los dos autores colombianos actuales con la obra autoficcional más consistente: Juan Diego Mejía (Medellín, 1952) y Fernando Vallejo. En el caso del primero, la indicación para la lectura de su obra en clave autoficcional consiste solamente en la identidad nominal proyectada textualmente; la visibilidad del autor no se enfoca en su figura sino en torno a su producción literaria. Quizás como efecto de lo anterior, se trata de un escritor cuya obra ha sido poco estudiada $^{26}$, en contraste con la abundancia de trabajos sobre la de Vallejo, en cuyo caso no se puede ignorar la imagen de sí mismo que ha construido extratextualmente, a través de gestos performativos, con ecos en su obra $^{27}$.

Con los anteriores ejemplos, se ha querido destacar una tendencia importante en cuanto a la constitución de las figuras de autor en los campos literarios y una pregunta sobre su impacto en la recepción tanto en términos cuantitativos como en relación con sus efectos en las expectativas de los lectores y sus modos de asumir los pactos de lectura.

En todo caso, se concuerda con Premat en que «el autor no es un concepto unívoco, una función estable ni, por supuesto, un individuo en el sentido biográfico» (p. 21), puesto que lo que figura en la obra no es el Autor, en tanto origen del signo, sino como parte de él, signo en sí mismo, si bien, uno que remite al Autor, fantasmática, ambigua, paradójica e, incluso, antitéticamente. Se trata de un

\footnotetext{
Hasta la fecha, el único estudio que aborda el carácter autoficcional de su obra es el de Escobar (2015).

$27 \quad$ A pesar de que en los trabajos críticos suele mencionarse estos gestos extratextuales, sobresale la ausencia de abordajes específicos de la performancia extratextual vallejiana y de su incidencia en la constitución de la figura del autor y en la producción de sentido respecto a su obra. Hay trabajos como los de Giraldo (2010), Klinger (2011), Cherri (2013) y Guerrero (2014) que abordan el problema de lo performativo, pero solamente a propósito de los personajes o la escritura.
} 
signo complejo, con múltiples semiosis:

(UNO) La figuración textual del autor, o bien reitera las percepciones públicas que se tienen de él, así sean tan solo las convenciones de autor, o bien construye otras convenciones, una imagen de sí que se integra a la obra, un simbolo.

(DOS) Lo que sigue el lector, lo que le insufla una actividad detectivesca, no es la presencia del Autor; es tan solo una hue1la, un indicio, un rastro que, en efecto, traza un camino, pero no es este el de la verdad factual.

(TRES) El rastro configura en sí mismo una especie de índice, el mapa de una travesía imaginaria que el autor se atribuye ambiguamente para que el lector, en su ánimo persecutorio, la experimente.

(CUATRO) El sintoma es un tipo de signo en el que, a través de la expresión de algo perceptible por los sentidos, se invita a representarse otra cosa no perceptible a simple vista: esto sería el psiquismo del autor, su ideología, su intencionalidad o sus motivaciones para (aparentar) volcarse en el texto. Sin embargo, el síntoma puede ser fingido, como se pueden impostar la risa, el llanto o el estornudo. Hay algo detrás del síntoma, que llama a la especulación o, con más herramientas, a la interpretación; pero no siempre es posible saber de qué se trata. Es decir, como síntoma, la proyección de la figura del autor no debería producir la pregunta de si vivió o no vivió lo narrado, sino por qué proyecta esa imagen más o menos distorsionada de sí mismo, a qué necesidades expresivas responde o qué efecto quiere lograr en el lector.

(CINCO) La puesta en relación con el autorretrato permite pensar la figuración imaginaria del autor como un ícono, una representación que, aunque puede remitir a alguna imagen reconocible que el lector tenga de él, así sea tan solo la de la solapa del libro, da a su imagen construida con palabras unos contornos que contienen su imagen, su silueta, el límite de su equivalencia en la representación y, al mismo tiempo, la desdibujan. Este parecer estar ahi imaginario atrae la mirada y escapa de ella y, en la tensión entre la representación de una figura y de su sombra, solamente deja la imagen de la incertidumbre.

La potencia significativa de este signo múltiple y complejo no es de poca envergadura, puesto que con la atención que atrae hacia sí el autor, de un modo recíproco, el lector gana mayor agencia, una posición más activa y vinculante: es él quien activa la potencia significativa de la ambigüedad y se ve orillado a acoger sus efectos de incertidumbre.

\section{Lector y efecto estético: incer- tidumbre y debilitamiento}

La primera cuestión en relación con el rol del lector frente al pacto ambiguo, es su actitud respecto a la búsqueda de equivalencias entre lo textual y lo extratextual. Al respecto, Casas (2014) cuestiona los abordajes que se centran excesivamente en el referente: «determinar hasta qué punto una obra es más o menos fiel con respecto a una vida, o hasta qué punto la proyección ficcional del autor hace justicia a la persona real, no aclara demasiado sobre el funcionamiento de un texto» ( $\mathrm{p}$. 11).

Sin embargo, la posición del lector es igual de ambigua que el pacto que se le propone. De un lado, parece ser inevitable para él seguir la proyección del autor en las páginas literarias, en tanto esta se constituye como indicio, huella, rastro, materia para el juego detectivesco; pero, de otro, si la persecución se lleva a cabo con una expectativa diferente a la del juego mismo, del como si, es decir, si se pretende alcanzar al autor factual, como hacen los personajes de Los detectives salvajes con Cesárea Tinajero, el resultado será su muerte, como en efecto ocurre cuando ella recibe el disparo dirigido a su lector y perseguidor, Ulises Lima (Bolaño, 1998). Quizás porque la especificidad del autor en el texto es su am- 
bigüedad, carácter que pierde si se le somete a otros rigores.

Aun así, tampoco se debe obviar que, del mismo modo que la novela histórica genera curiosidad respecto a la Historia, lo propio puede ocurrir con el lector que suscribe el pacto ambiguo en relación con la figura factual del autor. Esta actitud no tiene que ser vista como un vicio de lectura. Lo improcedente sería valorar la obra de acuerdo a su ajuste con lo factual (dentro del criterio verdad-mentira). Es en este punto en el que se mata al autor en tanto se le sustrae de la ambigüedad del pacto. El valor de las obras del pacto ambiguo reside precisamente en cómo sus efectos desestabilizan los modos (de conocimiento) lectores, amoldados a la dicotomía veraz/ficticio, al conducirlos a la incertidumbre y el debilitamiento de las expectativas de verdad.

Aquí se abordan las expectativas de certeza en torno a: (UNO) el otro y su intimidad, (DOS) la identidad y (TRES) el mundo; así mismo, se resalta (CUATRO) la mediación del discurso (ambiguo o de ficción) en el conocimiento al que el sujeto intenta acceder. Las antinomias propuestas son: (UNO) desnudo/velado; (DOS) presente/no presente; (TRES) omnisciente/ deficiente, respecto al universo narrado, y (CUATRO) realidad/discurso, en cuanto al lugar que ocupa el autor.
(UNO) Una de las potencias estéticas de las obras del pacto ambiguo se comparte con las escrituras del yo: la cuestión de la intimidad:

En los países de tradición católica, se tiene mucho miedo del yo, del Diablo y del orgullo, y la atención a sí mismo es sospechosa -de ahí proviene una cultura del secreto, y quizá, a causa de esta opresión, una práctica de lo íntimo más profunda y exigente que en los países protestantes donde el discurso sobre el yo, mejor admitido, queda quizá más superficial (Lejeune en entrevista a Alberca, 2004a).

La intimidad que exponen las escrituras del yo remite a la idea de desnudez, como gesto de honestidad, confidencia y, en algunos casos, exhibicionismo. Pero, para caracterizar los efectos específicos del 'desnudamiento' en el pacto ambiguo, al lado de los velos y filtros necesariamente implicados en las escrituras del yo del pacto autobiográfico, es necesario considerar los del novelesco, en el que coexisten fuerzas de volcamiento autobiográfico y de distanciamiento novelesco.

Siguiendo el planteamiento de Vargas Llosa respecto a que toda novela es, en algún grado, autobiográfica y en cada una de ellas hay un ejercicio de desnu- dez por parte del autor (1974), solo que el distanciamiento y la ficcionalización le permiten velarla o enmascararla; es razonable considerar que, en el caso de las obras del pacto ambiguo, la insinuación de la presencia de un autor que, como en el autorretrato, parece estar ahi diciendo «estoy desnudo, míreme», el lector pueda sentirse tentado a mirar, con pudor o abiertamente, incitado a saciar su pulsión voyerista, así sea para comprobar que la desnudez es ficticia o tan velada como en cualquier otro tipo de obra narrativa. Este guiño opera como una invitación que le da licencia para adentrarse entre los velos, si bien puede ser que descubra más su propia desnudez que la del autor. Lo que sí sería un error, como ya se ha insistido, es no darse cuenta de que, en el pacto ambiguo, la desnudez no es una promesa sino una provocación (Escobar, 2015).

La ambigüedad que supone el velamiento no anula el efecto de intimidad, sino que contrasta la desnudez con lo velado. El velo también es íntimo y connota el secreto. El texto exhibe, pues, una figura desnuda, sobre la cual se proyecta algún rasgo autoral, pero la figura se oculta detrás de una serie interminable de velos que el lector descorre sucesivamente sin alcanzarla. Es decir, se presenta la intimidad ajena como objeto de deseo, pero se trata de un objeto inalcanzable, una invitación a 
un lugar de imposible acceso y que remite al carácter de toda intimidad, como bien lo registra Cortázar (s.f. [1963]): «porque no sos mía, porque estás del otro lado, ahí donde me invitás a saltar y no puedo dar el salto, porque en lo más profundo de la posesión no estás en mí, no te alcanzo" (p. 329).

(DOS) Del mismo modo que el pacto ambiguo recuerda la imposibilidad de acceder al otro, la presencia-no presencia del autor arroja al lector al problema de la identidad como una ilusión. Amícola (2009) destaca que en estas formas «el artista pierde, con todo, sus contornos reales, pues se halla fabulando a partir de una base vital o, por el contrario, se desrealiza inventándose una nueva existencia desconectada de su pasado» (p. 190).

La pérdida del contorno erosiona o disuelve la expectativa de verdad afincada en la relación nombre propio-identidad, en tanto la autoficción «iría derecho a transgredir el último reducto del realismo: el nombre propio» (Alberca, 2005a, p. 117$)^{28}$ y con ello transgrede también la ilusión de identidad, «levanta, sin teorizaciones abstractas, la identidad como una ficción o la ficción de la identidad» (Alberca, 1999, p. 67), y la hace inestable en la medida en que, con Premat (2009), «el acto de escritura puede verse como una puesta en intriga de la identidad» (p. 12).

En cuanto al rol del lector, esta desrealización de la identidad, ceñida en el marco de la oposición verdadero/ficticio, lo puede conducir a reflexionar sobre lo que en efecto es el autor o cualquier sujeto. Para Premat (2009), «la inestabilidad de la identidad de la instancia que escribe se materializa en esa ficción, que no fija rasgos unívocos sino que acompaña la polisemia y ambigüedad del texto» (p. 13). De este modo, se puede cuestionar si la identidad del autor, buscada entre velos, reside en lo que recogen su nombre y demás rasgos identitarios, lo que el autor dice ser, lo que ha sido -su trayectoria-, lo que planea, la imagen que proyecta mediáticamente, sus fantasías de sí mismo proyectadas a través del texto, la idea que el lector tiene sobre él o sobre lo que debería encarnar el oficio de escritor... Esta serie de cuestionamientos implicaría un desplazamiento en las concepciones de la identidad hacia el reconocimiento de su carácter efímero y la disolución del ser en el devenir o, más precisamente, en el discurrir.

(TRES) Del mismo modo que se disuelve el sujeto, se disuel- ve el mundo que narra. La forma autoficcional, en particular, supone un narrador en primera persona, opuesto, en cuanto al poder sobre la información, al omnisciente. Justamente, esta limitación es la que Vallejo aprecia y por la que rechaza la omnisciencia:

¡Cómo va a saber un pobre hijo de vecino lo que están pensando dos o tres o cuatro personajes! ¡No sabe uno lo que está pensando uno mismo con esta turbulencia del cerebro va a saber lo que piensa el prójimo! ¡Al diablo con la omnisciencia y la novela! [...] Yo sólo creo en quien dice humildemente yo y lo demás son cuentos (Vallejo, 2003, contracarátula).

Aun dentro de este marco, la expectativa del lector frente a un narrador autodiegético es que diga la verdad sobre sí mismo y sobre su mundo; semejante expectativa se derrumba en tanto dicho narrador empieza a dejar ver que no sabe: puede ser equisciente o deficiente en su alusión a la realidad de la que hace parte (como ocurre, por ejemplo, con los narradores de El túnel de Sábato y «Macario» de Rulfo). Así revela su incapacidad para decir la verdad sobre sí mismo y sobre las cosas que le atañen, porque la realidad

$28 \quad$ Alberca atribuye esta idea a Darrieussecq (1996). 
excede sus posibilidades de aprehensión, así como las de cualquier sujeto ${ }^{29}$, en la narración del mismo modo que en la vida $^{30}$.

(CUATRO) La cuarta antinomia tiene que ver con la proyección de un ser real en el discurso, es decir, su proyección como signo y el hecho de que, al fin de cuentas, el signo es todo a lo que el lector puede acceder. El yo se hace discurso. Así, el lugar que ocupa el autor proyectado en el texto es el del sujeto, en el sentido de Barthes (1987 [1968]): «el lenguaje conoce un sujeto y no una persona» (p. 68) $)^{31}$.

Este sujeto, de acuerdo con Villena (2005), se hace ficción:

Las consideraciones teóricas en torno a la autoficción resituaron la agencia en el discurso en lugar de en el sujeto, al concebir el discurso como rearticulación de una experiencia desestructurada. El marco cognoscitivo cambia radicalmente y muestra al sujeto, en este contexto, como una ficción al igual que la vida autoficcional representada (p. 46).

Es decir, mientras la realidad se resiste a dejarse contener a través de categorías, teorías, ideologías o cualquier modelo humano de aprehensión, lo mismo ocurre con el individuo, $s u$ jeto de tales modos de conocer y limitaciones: su única consistencia es a través del discurso ${ }^{32}$. En el mismo sentido, Del Pozo (2009) asocia la autoficción con «la voluntad de conversión del yo en escritura» (p. 91) y Premat (2009) destaca que «el autor es a la vez el origen del texto y su producto; es un origen paradójico que se define a posteriori» y se «fabrica con los mismos materiales fantasmáticos que la ficción» (p. 26), es decir, es un efecto textual.

Así, el afán de veracidad y el paradigma referencialista son subvertidos a partir de

la perspectiva que considera al sujeto como un agente desestabilizado que se representa a través de discursos; de este modo, la ficción no puede descalificarse como forma de autorrepresentación al ser el sujeto ya no una especificidad sino una multiplicidad de posiciones articuladas por medio de un discurso (Villena, 2005, p. 41).

En fin, se ha postulado una serie de antinomias que suponen solapamientos y desplazamientos entre sus términos, con lo cual se sitúa al lector frente a la incertidumbre y el debilitamiento de la verdad: el acceso al otro, deseado pero imposible; la identidad, móvil, inestable, elusiva; la mirada, deficiente ante la expectativa de verdad u objetividad; y la figura autoral, disuelta como sujeto del (en el) discurso e, incluso, como ficción. A través de cada desplazamiento, se desautomatiza el rol del lector respecto al pacto literario (Pérez, 2012, p. 8) y se rompen los esquemas receptivos del lector $\mathrm{o}$, al menos, se los hace vacilantes (Alberca, 2005a, p. 119). El principal esquema que se rom-

29 Con Lacan (2010 [1953-1963]), lo real excede las posibilidades de lo simbolizable.

30 Por ejemplo, el narrador autoficcional de Juan Diego Mejía parece eludir la limitación de la primera persona y simular los poderes de la omnisciencia, pero deja a la vista la simulación. No se propone un pacto de objetividad, sino uno en el que se exponen las costuras del tránsito hacia lo imaginario, como forma de donar sentido a las situaciones que sobrepasan su conocimiento. De allí que, el pacto que se propone en su obra constituya un sucedáneo débil del pacto en la novela de narrador omnisciente (Escobar, 2015), tan débil que, a través de la aspiración de la búsqueda imaginaria de omnisciencia, revela su carácter deficiente: no sabe, y es por eso que no le queda otro recurso que imaginar.

31 Según Michaud (1999), esto también es válido para la escritura autobiográfica: «sólo a través de la escritura, y no de la memoria que es solamente su soporte, se abre paso la verdad del sujeto, tan inasible como es» (p. 99).

32 Esto no es más que otra constatación, en el marco de las estéticas contemporáneas, de la tendencia del pensamiento occidental (de la filosofía clásica a la moderna y a la contemporánea: Descartes, Kant, Nietzsche, Freud, Lacan, Foucault, Vattimo) a trasladar la atención de la realidad al discurso; es decir, a cuestionar su abordaje como un objeto independiente, primero, del sujeto que la percibe; $y$, segundo, del discurso a través del cual la construye. 
pe es la ilusión de que se pueda oponer radicalmente la realidad a la fantasía, es decir, que se puede afirmar qué es lo real de un modo absoluto y definitivo ${ }^{33}$.

La transformación del ser como ousia, su renuencia a dejarse estancar bajo categorías identitarias fijas y esencialistas, su transitoriedad, su muerte constante, su realización-desrealización a través del discurso, llevan la expectativa de veracidad al único destino posible: la incertidumbre.

Esta, como efecto del pacto ambiguo, queda magistralmente elaborada en dos autorretratos: el Autorretrato (1646) de Johannes Gumpp (1626-1728) y el Triple autorretrato (1960) de Norman Rockwell (18941978). En ellos, el artista no revela su rostro sino dos proyecciones (y dos mediaciones): en el espejo y en el lienzo. Se niega la visión directa del rostro del artista y se destacan, entonces, el carácter incierto del yo retratado y su dimensión enigmática. Bell (2004) dice que Gumpp «pinta el espejo, el lienzo y al pintor encerrados en un círculo cerrado, y la esperanza de realizar una autorrepresentación va $\mathrm{y}$ viene de uno a otro». El pintor se mantiene de espaldas, como diciendo: «lo que yo soy no podéis verlo» (p. 10).

La incertidumbre y la inestabilidad son los efectos que mejor recogen el sentido de las búsquedas de las literaturas del pacto ambiguo y que mejor explican la ruptura de los esquemas de recepción. Al lector no le queda más remedio que aceptar que toda indagación, toda persecución tras el rastro del autor o en pos de su fantasma, todo intento de desvelamiento de su figura factual, no lleva a otro lugar. Este lugar se enmarca en la epistemología de las estéticas débiles $^{34}$, la cual conduce a

rememorar el sentido del ser y reconocer que este sentido es la disolución del principio de realidad en la multiplicidad de las interpretaciones, precisamente para ser capaces de vivir sin neurosis la experiencia de esta disolución, escapando a la recurrente tentación de 'retornar' a un más fuerte (más asegurador y a la vez más amenazante y autoritario) sentido de lo real (Vattimo, 2004, p. 36).

El trabajo de la interpretación se torna, de este modo, infinito, incompleto, imposible... e indispensable, puesto que «instaura sentido sin cesar, pero siempre acaba por evaporarlo» (Barthes, 1987 [1968], p. 70).

\section{Conclusiones}

Este artículo se ha concentrado en tres asuntos: el objeto de los estudios que se ocupan de la autoficción y el pacto ambiguo, la particularidad de la relación autor-obra-lector en el marco de este pacto, y los efectos estéticos y de sentido a los que tiende este tipo de literaturas.

Respecto al primer asunto, se han señalado los límites y exclusiones de la conceptualización canónica de la autoficción $\mathrm{y}$, a través de su diferenciación respecto al pacto ambiguo y de la consideración de lo autoficcional no solo como forma, sino también como clave de lectura, se ha llamado la atención respecto a un rango de figuraciones de autor más amplio que el usualmente contemplado por la

33 Esta tendencia, sin embargo, tiene detractores: Alberca (2014) cuestiona el excesivo relativismo posmodernista que ha conducido a teñir de ficción cualquier intento de abordar la realidad, con énfasis, desde luego, en las exploraciones autobiográficas, por lo cual anuncia el fin de la autoficción y la vuelta a la autobiografía, como antificción (término de Philippe Lejeune), orientada a «contar la verdad y solo la verdad» (p. 163). Su denuncia no deja de ser un llamado a asumir posturas más mesuradas, puesto que el abordaje de lo real sigue siendo un reto necesario, especialmente en tiempos en los que la manipulación a través del discurso, en lo que se viene denominando posverdad, usurpa el lugar de los hechos y del intercambio riguroso de argumentos acerca de cómo interpretarlos. Por otra parte, tampoco es deseable el retorno a los modos autoritarios y dogmáticos en los que se ha abordado y con los cuales se han justificado las violencias, modos frente a los cuales las literaturas actuales y, en especial, las del pacto ambiguo enseñan su profundo escepticismo.

34 La cuestión del debilitamiento (de la verdad y la identidad) como efecto de la autoficción, es desarrollada en Escobar (2015). 
teoría de la autoficción en su sentido más estricto.

En la medida en que el pacto ambiguo es resultado de una diversidad de guiños y provocaciones que el autor dirige a su lector y con los cuales alimenta sus expectativas lectoras, se ha caracterizado el guiño como clave de lectura autoficcional; se ha ahondado en el carácter sígnico de las figuraciones de autor proyectadas en las obras, para remarcar la distancia entre el signo (el yo ficcional) y aquello a lo que alude ambiguamente (el yo factual), y se ha reflexionado sobre el rol que el pacto ambiguo demanda de los lectores que lo suscriben.

Finalmente, se han atendido algunas antinomias que derivan de la ambigüedad de la presencia autoral en el texto, en torno a la intimidad ajena, la identidad, el dominio del universo narra- do y la veracidad, con el ánimo de señalar cómo, frente a todas ellas, la incertidumbre se erige en efecto de sentido, con lo cual, las formas del pacto ambiguo participan de la tendencia artística contemporánea hacia estéticas débiles. Esta inestabilidad, esta debilidad del pacto, constituye su fortaleza ética, en contraposición a los textos que todavía se pretenden sólidos y verdaderos.

\section{Referencias}

Alarcón, J. (2014). Una autoficción sin identidad: reflexiones en torno a la autoficción especular En: A. Casas (ed.), La autoficción en los estudios hispánicos: perspectivas actuales. El yo fabulado. Nuevas aproximaciones críticas a la autoficción. Madrid/Frankfurt: Iberoamericana Vervuert.

Alberca, M. (1996). El pacto ambiguo. ¿Es literario el género autobiográfico? Boletín de la Unidad de Estudios Biográficos, (1), 9-18.

Alberca, M. (1999). En las fronteras de la autobiografía. En: M. Ledesma, Escritura autobiográfica y géneros literarios. Jaén: Universidad de Jaén.

Alberca, M. (2004a). Entrevista a Philippe Lejeune. Cuadernos Hispanoamericanos, (649-650), 271278. Recuperado el 10 de junio de 2012, de http://autoficcion.es/?page id=47.

Alberca, M. (2004b). La invención autobiográfica: premisas y problemas de la autoficción. En: M. Á. Hermosilla y C. Fernández (eds.), Autobiografía en España, un balance: Actas del Congreso Internacional celebrado en la Facultad de Filosofía y Letras de Córdoba del 25 al 27 de Octubre de 2001. Madrid: Visor Libros.

Alberca, M. (2005a). ¿Existe la autoficción hispanoamericana? Cuadernos del CILHA (Centro Interdisciplinario de Literatura Hispanoamericana), 7(7-8), 115-127. Recuperado el 8 de junio de 2012, de http://www.redalyc.org/src/inicio/ArtPdfRed.jsp?iCve=181720523003.

Alberca, M. (2005b). Propuesta para una lectura transitiva de César Aira. Cuadernos Hispanoamericanos, (665), 83-94. 
Alberca, M. (2007). El pacto ambiguo. De la novela autobiográfica a la autoficción. Madrid: Biblioteca Nueva.

Alberca, M. (2014). De la autoficción a la antificción. Una reflexión sobre la autobiografía española actual. En: A. Casas (ed.), La autoficción en los estudios hispánicos: perspectivas actuales. El yo fabulado. Nuevas aproximaciones críticas a la autoficción (pp. 149-168). Madrid/Frankfurt: Iberoamericana Vervuert.

Álvarez, M. (ed.) (2013). Imágenes conscientes. AutoRepresentacioneS\#2. Binges: Orbis Tertius.

Amícola, J. (2009). Autoficción, una polémica literaria vista desde los márgenes (Borges, Gombrowicz, Copi, Aira). Olivar, 12, 191-207. Buenos Aires: Universidad Nacional de la Plata. Recuperado el 8 de junio de 2012, de http://www.memoria.fahce.unlp.edu.ar/art_revistas/pr.3713/pr.3713.pdf

Bajtín, M. (1989 [1935]). La palabra en la novela. En: Teoría y estética de la novela .\& ., trads.. Madrid: Taurus.

Barthes, R. (1987 [1968]). La muerte del autor. En: El susurro del lenguaje. Barcelona: Paidós.

Bell, J. (2004). 500 autorretratos. New York: Phaidon.

Bellour, R. (1990). L Entre-images: Photo, Cinéma, Vidéo. París: La Différence.

Bolaño, R. (1998). Los detectives salvajes. Barcelona: Anagrama.

Cabo, F. (2014). Teatralidad, itinerancia y lectura: sobre la tradición teórica de la autoficción En: A. Casas (ed.), La autoficción en los estudios hispánicos: perspectivas actuales. El yo fabulado. Nuevas aproximaciones criticas a la autoficción (pp. 25-43). Madrid/Frankfurt: Iberoamericana Vervuert.

Casas, A. (2014). Introducción En: A. Casas (ed.), La autoficción en los estudios hispánicos: perspectivas actuales. El yo fabulado. Nuevas aproximaciones críticas a la autoficción (pp. 7-21). Iberoamericana Vervuert, Madrid/Frankfurt am Main.

Cherri, C. L. (2013). Enunciación performática y politización estésica en La virgen de los sicarios de Fernando Vallejo. Aisthesis, (53), 127-140.

Colonna, V. (2004). Autofiction et autres mythomanies littéraires. Auch: Tristam.

Cortázar, J. (s.f. [1963]). Rayuela. Bogotá: Fundación Promotora Colombiana de Cultura.

Cortázar, J. (1994 [1979]). Lucas, sus discusiones partidarias. En: Cuentos completos 2. Madrid: Alfaguara. 
Dalí, S. (2010 [1964]). Diario de un genio. Barcelona: Tusquets.

Darrieussecq, M. (1996). L'autofiction, un genre pas sérieux. Poétique, (107), 369-380.

Diaconu, D. (2010). El pacto autoficcional en El río del tiempo de Fernando Vallejo. Apuntes para una estética de la provocación neoquínica. Literatura: teoría, historia, crítica, 12, 221-258.

Diaconu, D. (2013). Fernando Vallejo y la autoficción. Coordenadas de un nuevo género narrativo. Bogotá: Universidad Nacional de Colombia.

Del Pozo, A (2009). La autoficción en París no se acaba nunca de Enrique Vila-Matas. $452^{\circ} \mathrm{F}$ : Revista de teoría de la literatura y literatura comparada, (1), 89-103.

Doubrovsky, S. (1988). Autobiographiques. París: PUF.

Escobar-Vera, H. (2015). Juan Diego Mejía: hacia una «estética débil». Bogotá: Universidad Autónoma de Colombia.

Escobar-Vera, H. (2016). Dalí, un genio hacia la muerte. Grafia, 13(2), 98-128.

Foucault, M. (2002 [1984]). ¿Qué es la ilustración? ., trad.. Señal que cabalgamos, (5), 14-35.García, J. (2009). (Im)posibilidades del drama autobiográfico (El álbum familiar y Nunca estuviste tan adorable). En: O. Pellettieri (ed.), En torno a la convención y a la novedad (pp. 93-104). Buenos Aires: Galerna.

García, J. (2014). Paradojas de la autoficción dramática. En: A. Casas (ed.), La autoficción en los estudios hispánicos: perspectivas actuales. El yo fabulado. Nuevas aproximaciones críticas a la autoficción (pp. 127-148). Madrid/Frankfurt: Iberoamericana Vervuert.

Gasparini, P. (2004). Est-il je? Roman autobiographie et autofiction. París: Seuil.

Gasparini, P. (2008). Autofiction. Une aventure du langage. París: Seuil.

Giraldo, D. (2010). Subversión discursiva y sexual en La Virgen de los sicarios de Fernando Vallejo. (Tesis de grado). Universidad de Montreal, Montreal, Canadá.

Gómez-Tarín, F., y Rubio-Alcover, A. (2013). Narrador fílmico y autoficción: nuevas posibilidades del punto de vista. En: Actas del V Congreso Internacional Latina de Comunicación Social. Tenerife: Universidad de La Laguna.

Goyarrola, É. (2016). Autorreferencialidad en la fotografía contemporánea: Francesca Woodman, Antoine d'Agata y Alberto García-Alix. (Tesis doctoral). Universitat Pompeu Fabra, Barcelona, España. 
Guerrero, J. (2014). Tecnologías del cuerpo. Exhibicionismo y visualidad en América Latina. Madrid-Fankfurt: Iberoamericana-Vervuert.

Hernández, A. A. (2016). El diario de un escritor en Encuentro en Saint-Nazaire de Ricardo Piglia. La Palabra, (28), 75-90. Ingarden, R. (2005 [1937]). La comprehensión de la obra de arte literaria. México: Universidad Iberoamericana.

Juliá, M. (2006). Las ruinas del pasado: aproximaciones a la novela histórica posmoderna. Madrid: Ediciones de la Torre.

Klinger, D. (2011). La reconfiguración de la cultura moderna de las letras. En: T. Cámara y Di Leone (eds.), Experiencia, cuerpo y subjetividades: nuevas reflexiones. Literatura argentina y brasileña del presente. Buenos Aires: Santiago Arcos.

Lacan, J. (2010 [1953-1963]). De los nombres del padre. Buenos Aires: Paidós. Lecarme, J. (1993). L'autofiction: un mauvais genre? RITM. Recherches interdisciplinaires sur les textes modernes, (6), 227-249.

Lejeune, P. (1994 [1975]). El pacto autobiográfico. En El pacto autobiográfico y otros textos. Madrid: Megazul-Endumion.

Lejeune, P. (1994 [1986]). El pacto autobiográfico (bis). En El pacto autobiográfico y otros textos. Madrid: Megazul-Endumion.

Martín, G. (ed.) (2008). Cineastas frente al espejo. Madrid: T \& B Editores.

Martínez, J. (2014). Autoficción y docuficción como propuestas de sentido. Razones culturales para la representación ambigua. Castilla. Estudios de Literatura, (5), 26-38.

Meizoz, J. (2007). Postures littéraires. Mises en scène modernes de l'auteur. Génova: Slatkine.

Michaud, G. (1999). L'autobiographie comme conversion esthétique: les derniers écrits de Gabrielle Roy. Littérature, (113), 95-114.

Muñoz, R. (2016). Fernando Vallejo: Vindicación del bíos kynikós y el kynikós trópos en treinta años de novelística (Tesis doctoral). Universidad de Antioquia, Medellín, Colombia.

Musitano, J. (2010). Ironía y autoficción en la narrativa de Fernando Vallejo. En Actas del II Coloquio Internacional "Escrituras del yo". Rosario: Centro de Estudios de Teoría y Crítica Literaria, Centro de Estudios de Literatura Argentina.

Pardo, R. (2012). El otro yo: de la autoficción al turismo identitario. Revista Sans Soleil, (4), 74-93.

Pérez, C. (2012). El pacto literario como lugar de encuentro. Mercurio Peruano, (525), 21-46. 
Pérez, M. L. (2008). El autorretrato o la identidad ante la cámara fotográfica. Valencia: Sl.

Pozuelo, J. M. (2010). Figuraciones del yo en la narrativa. Javier Marías y E. Vila-Matas. Valladolid: Cátedra Miguel Delibes.

Puertas, F. E. (2003). La escritura autobiográfica en el siglo XIX: el ciclo novelístico de Pío Cid considerado como la autoficción de Ángel Ganivet (Tesis doctoral). Universidad Nacional de Educación a Distancia, Madrid, España.

Premat, J. (2009). Héroes sin atributos: Figuras de autor en la literatura argentina. Buenos Aires: Fondo de Cultura Económica.

Priego, C. (1985). Algunas reflexiones sobre el autorretrato. Liño: Revista anual de historia del arte, (5), 177-204.

Quílez, L. (2008). Sutiles pretéritos: (post)memoria(s) y (auto)biografía(s) en el documental contemporáneo. En: G. Martín (ed.), Cineastas frente al espejo. Madrid: T \& B Ediciones.

Ramírez, J. A. (2003). Yo mismo. Automodelo e identidad quebrada. Exit, (10), 17-35.

Rulfo, J. (2000 [1953]). Macario. En: El llano en llamas. Madrid: Cátedra.

Sábato, E. (1968 [1948]). El túnel. Buenos Aires: Sudamericana.

Sánchez, M. (2010). Entre la autoficción y la biografía novelada. Narrativa española de la memoria. En: Actas del II Coloquio Internacional de Escrituras del yo. Rosario, Argentina. Recuperado el 18 de noviembre de 2015, de http://www.celarg.org/int/arch_coloquios/s_nchez_acta.pdf

Searle, J. R. (2001 [1969]). Actos de habla: ensayos de filosofía del lenguaje (., trad. Madrid: Cátedra. Sloterdijk, P. (2003 [1983]). Crítica de la razón cínica. Madrid: Siruela.

Trastoy, B. (2006). La escritura autobiográfica en el escenario y en la pantalla: una cuestión de estilos (Acerca de Notas de tango de Rafael Filippelli). Telón de fondo. Revista de teoría y crítica teatral, (4), 1-14. Recuperado de http://www.telondefondo.org/download.php?f=YXJjMi84MS5wZGY=\&tipo=articulo\&id=81.

Tabachnik, S. (2012). Sobre la alteración lúdica de las imágenes en la era del fotoshop. Adversus, 9(22), 122-134.

Toro, V. (2010). La auto(r)ficción en el drama. En: V. Toro, S. Schlickers y A. Luengo (eds.), La obsesión del yo. La auto(r)ficción en la literatura española y latinomericana (pp. 229-250). Madrid/ Frankfurt: Iberoamericana/Vervuert.

Vallejo F. (2003). Los dias azules. Bogotá: Alfaguara. 
Vargas Llosa, M. (1974). La novela. Buenos Aires: América Nueva.

Vattimo, G. (2004 [1990]). Posmodernidad, tecnología, ontología. En: Nihilismo y emancipación. Ética, politica, derecho. Barcelona: Paidós.

Vilain, P. (2005). Défense de Narcisse. París: Grasset.

Villena, F. (2005). Discursividades de la autoficción y topografias narrativas del sujeto posnacional en la obra de Fernando Vallejo. (Tesis doctoral). Ohio State University, Ohio, EE.UU. Recuperado el 8 de junio de 2012, de http://etd.ohiolink.edu/view.cgi?acc_num=osu1117467762 